\title{
Cropping pattern simulation-optimization model for water use efficiency and economic return
}

\author{
Cesar Augusto Terán-Chaves, Sonia Mercedes Polo-Murcia \\ Corporación Colombiana de Investigación Agropecuaria (AGROSAVIA), C.I. Tibaitatá, Colombia
}

\begin{abstract}
Sustainable agricultural development is one of the most important tools for the economic growth of a country. Therefore, water and land use management is considered a priority. This research aimed to develop a framework to optimize crops' spatial and temporal distribution in an irrigation district. The AquaCropOS (FAO) water productivity model was integrated with a nonlinear optimization model to maximize the annual net profitability and minimize the water consumption of three crops (rice, corn, and forage). It was applied at a regional level to 905 simulation sub-units in the Zulia irrigation district (Colombia), in three typical climatic years' scenarios, and at a multi-period level (monthly). The results indicated that: i) crop simulation for the study area was applicable and feasible; ii) rice can be combined with forage and corn; iii) corn is a viable option under dry year conditions; iv) under a wet year, forage production is the best option. On average, in the dry year, profitability decreased by $14.5 \%$ compared to the normal year in half of the study area, and in some areas, economic losses of up to $53 \%$ were obtained. In the wet year, profitability remained at the same level as the normal year in $43.8 \%$ of the area. However, there were significant decreases in profitability in $23.1 \%$ of the district. In the normal year, the water demand of the crops in each simulated period allows savings of up to $50 \%$ of water compared to the current concession amount, which is 1000 $\mathrm{mm}$. This study is useful for making decisions on sustainable
\end{abstract}

Correspondence: César Augusto Terán-Chaves, Corporación Colombiana de Investigación Agropecuaria (AGROSAVIA) C.I. Tibaitatá, Km 14, vía Mosquera-Bogotá, 250040 Cundinamarca, Colombia. E-mail: cteran@agrosavia.co

Key words: AquaCrop-OS; nonlinear optimization; profitability; spatial distribution; water availability.

Acknowledgements: this research was supported by AGROSAVIA Corporación Colombiana de Investigación Agropecuaria. The authors are thankful to the editor and anonymous reviewers for their constructive comments that helped us greatly improve the manuscript quality.

Received for publication: 6 May 2021.

Accepted for publication: 19 August 2021.

${ }^{\circ}$ Copyright: the Author(s), 2021

Licensee PAGEPress, Italy

Journal of Agricultural Engineering 2021; LII:1197

doi:10.4081/jae.2021.1197

This article is distributed under the terms of the Creative Commons Attribution Noncommercial License (by-nc 4.0) which permits any noncommercial use, distribution, and reproduction in any medium, provided the original author(s) and source are credited. resources management and optimal irrigation water and land use under different biophysical and economic conditions.

\section{Introduction}

Colombian's agriculture sector has grown at an impressive rate. This sector accounted for $6.7 \%$ of the national gross domestic product (GDP) in 2019. The agriculture sector went from a total value of 14.81 billion USD in 2000 to 24.70 billion USD in 2019. (World Bank, 2020). The recent growth in agricultural production may result from increases in either the area cultivated or the crop productivity. However, current land use levels correspond to a lower use intensity than optimal use or land use capacity (Sylvester et al., 2020).

Colombia is one of the countries with the highest number of water resources in the world. It has five mayor macro basins: Caribe, Pacific, Magdalena, Cauca, Orinoquía and Amazonia. However, the spatial and temporal availability of fresh water at both the regional and local levels is affected by low irrigation coverage in crops, high variability in available flows, seasonality of rains, low irrigation efficiency, presence of drought, and water excess. The agriculture sector requires 16,067 million $\mathrm{m}^{3}$ of water per year, of which $10 \%$ is supplied by irrigation and $90 \%$ by rainwater (IDEAM, 2018).

Both the lack of water resources planning and the low access to irrigation water reduce crops productivity. Land use planning is one of the most effective instruments to optimize the allocation of resources, improve the natural environment and achieve the sustainable development of the economy, society, and ecology in a watershed (Ouyang et al., 2016). The spatial variability of agricultural production and income is mainly dependent on the biophysical and economic conditions of farmers in each location.

Regional planning of crop planting can be attributed to the need for optimal use of local production resources and the provision of solutions to balance supply and demand in decision-making (Mardani et al., 2019). Therefore, climate change and variability, together with rapid economic development, are fundamental elements of optimization models for the spatial distribution of crops (Rădulescu and Rădulescu, 2012).

Seeding area and several crops ratio optimization can be obtained through mathematic programming tools. For this purpose, an objective function that reaches an extreme value under the condition of satisfying specific restrictions needs to be defined (Liu et al., 2019; Pei et al., 2021). Some of the most common mathematic programming methods for optimization include linear programming, nonlinear programming, dynamic programming, integers programming, binary programming, critical path method, and assignment method.

Various studies have been in crop planning in agriculture. He et al. (2020) developed a spatial optimization model defined by the economic net profits produced per unit of irrigated water. 
Moreover, it presented results for a baseline year (2015) and a planning year (2020). Similarly, Pei et al. (2021) proposed a twostage optimization model for the crop's spatial distribution from the supply and demand perspective. Previous studies mostly took economic benefits, supply, and demand balance as evaluation indexes.

One of the significant drawbacks of optimization models has the over-simplification of crop growth and yield. Therefore, in recent years, developed models that allow the crops optimal distribution based on soil heterogeneity and irrigation water allocation (Daghighi et al., 2017; Kuschel-Otárola et al., 2018; Pahmeyer et al., 2021).

Despite this progress, previous optimization models integrated crop growth simulation model used the crop function proposed by Doorenbos and Kassam (1979), which relates the yield reduction because of the relative water loss due to evapotranspiration. This water productivity approach requires the yield response factor (Ky) under local conditions, which it might carry out field experiments is expensive, laborious, and time-consuming.

Such studies successfully helped implement the optimization model with principal factors of the crop. Which inspired us that the optimization spatial of crops can be generated based on simulation models complementary to the empirical relationships (Steduto et al., 2009), considering the spatiotemporal heterogeneity of agricultural climate. Also, results can offer reproducible and reliable mapped estimations of low cost. Thus, crop growth simulation models facilitate the evaluation of agricultural production under a range of possible environmental conditions.

Among the crop growth simulation, an existing model is AquaCrop (Raes et al., 2009; Steduto et al., 2009), which can be applied to a wide variety of herbaceous crops (Bello and Walker, 2016; Hadebe et al., 2017; Zeleke, 2019; Yeşilköy and Şaylan, 2020). In addition, foster et al. (2017) developed the model AquaCrops-OS for the geo-spatial crops modelling, which reduces the execution time of large-scale simulations.

AquaCrop-OS model can be combined with the optimization nonlinear model to complete the dynamic optimization of time and space. It is necessary to carry out relevant research of adaptability, make full use of the regional precipitation resources and choose cropping system reasonably, ensuring sustainable agricultural development.

We ask the following research questions: Given a limited number of resources, how does the interannual variability of the water regime affect agricultural profits? What is the optimal irrigation water demand, and how should water be allocated to crops? What is the impact of water management practices that increase and/or decrease water availability for crops production?

The goal of this study was to develop in three regional hydrological scenarios [i) wet year; ii) dry year; iii) normal year] an operational framework to optimize the spatial distribution of crops, considering both the supply/demand of biophysical resources and the economic conditions of the farmers. An irrigation district of Colombia was considered as a case study. In the first place, information about the area's agricultural production, climate, and soils was collected. Next, AquaCrops-OS was used to model biomass development and productivity. The optimal crop distribution and sowing period were determined by using nonlinear programming. Finally, a k-means cluster analysis was developed to facilitate interpreting results at a multi-period and spatial level.

This study is original in relating the simulation of the growth of forage, corn, and rice crops with AquaCrop-OS generating a biophysical and economic optimization of the planted areas under different agroclimatic scenarios. Furthermore, we estimate the losses or relative gains in the production of the crops studied. This work can provide a scientific reference for governmental settings to formulate, implement, evaluate, or change agricultural policies in future vulnerability to climate change.

\section{Materials and methods}

Four main stages were developed to integrate the methodology and simulation-optimization models (Figure 1). In the first stage (A), a compilation of the study area's climatic, edaphic, and economic information was carried out. In the second stage (B), the model AquaCrop-OS was executed to simulate the production of the crops, and a preprocessing of the economic and water availabil-

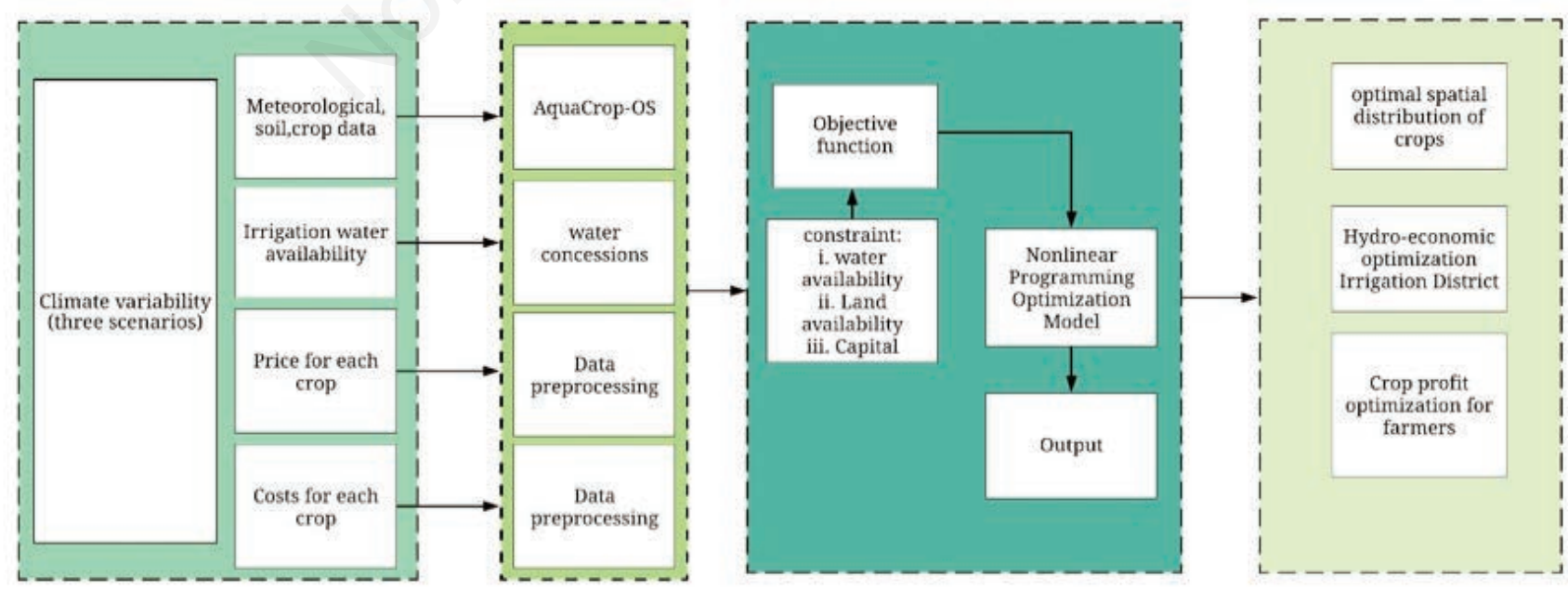

A

B

c

D

Figure 1. A-D) The framework of simulation-optimization model. 
ity data in the study area was carried out. Finally, in the third stage (C), the nonlinear programming model was run in Pyomo 5.7.1 (Hart et al., 2017), an open-source mathematical modelling language based on Python. It allows obtaining an optimal cropping pattern subject to water, capital, market, and labour constraints.

Finally, a cluster analysis was performed to facilitate the interpretation of the results at a multi-period and spatial level. In this phase, the results net profitability of different cropping patterns was clustered using a k-means algorithm. This algorithm aims to partition $\mathrm{n}$ observations into k clusters in which each observation belongs to the cluster with the nearest mean. GeoDa (Anselin et al., 2006) tool was utilized in this study to assess the k-means. GeoDa implements the cluster algorithms by leveraging the $C$ Clustering Library (Hoon et al., 2017), augmented by the kmeans++ algorithm from Arthur and Vassilvitskii (2007).

\section{AquaCrop-OS model}

The AquaCrop model was developed by the Food and Agriculture Organization of the United Nations (FAO). This model allows simulating the yields of herbaceous crops as a function of the amount of transpired water by the crop under different irrigation and dryland conditions (Steduto et al., 2009).

To simulate the daily growth and development of the crops, AquaCrop requires information on local air temperature, reference evapotranspiration (ETo), rainfall, atmospheric $\mathrm{CO}_{2}$ data, and Crop characteristics; also, irrigation method, soil profile, and field management containing characteristics of the field on which the crop is cultivated. In this model, crop parameters are differentiated as conservatives and non-conservatives.

Conservative parameters are inherent to the species and relatively stable. The most important are canopy growth coefficient (CGC); canopy decline coefficient (CDC); crop coefficient (Kcb) for complete coverage transpiration; normalized water productivity (WP*) for biomass formation; coefficients to adjust the harvest index (HI) in relation to the inhibition of the leaf growth and conductance of stomata; and soil water depletion thresholds for leaf growth inhibition, stomata conductivity, and canopy senescence acceleration. The non-conservative parameters depend on the environmental conditions, the handling decisions, and cultivated varieties.

The AquaCrop model has five available versions: standard, plug-in, GIS, R, and OS (Steduto et al., 2009; Lorite et al., 2013; Foster et al., 2017). In this study, the version AquaCrop-OS (Open Source) was used, and it was addressed with the software Octave to adapt it to the information volume and allow parallel simulations of multiple points.

\section{Nonlinear programming model with multi-period and spatial analytic approach}

The basic structure of the objective function, which goal is to maximize profits, is derived from the study of Kuschel-Otárola et al. (2018) (Eq. 1). The calculation of the annual net profit from agriculture production for each simulation sub-unit in the proposal model has different components. The first component of this equation is related to calculating the net profit from the sales of the crops within the irrigation district. The crop yield is calculated with the AquaCrops-OS model. The second component is related to the labour cost. The third component is related to the cost of inputs, and the fourth component is related to the cost of irrigation water.

$$
\begin{aligned}
& \operatorname{Max} \pi=\sum_{j=1}^{J} P_{j} A_{j} Y_{j}-L_{c} \sum_{j=1}^{J} \sum_{t=1}^{T} A_{j} L_{j t}- \\
& -\sum_{j=1}^{J} \sum_{t=1}^{T} A_{j} C I_{j t}-C R \sum_{j=1}^{J} \sum_{t=1}^{T} A_{j} R_{j t}
\end{aligned}
$$

$Y_{j}=\left[W P^{*} \sum \frac{T r}{E T o} * H I\right]_{j}$

where:

j: represents crop type (1: Corn;2: Rice; 3: Forage grass);

t: month sown (1 to 12$)$;

$\mathrm{P}_{\mathrm{j}}$ : Price per unit of crop j product, in USD $\mathrm{t}^{-1}$;

$\mathrm{A}_{\mathrm{j}}$ : Harvested crop j area, in hectares (ha);

Yj: crop yield $\left(\mathrm{t} \mathrm{ha}^{-1}\right)$;

WP*: Water productivity normalized by weather $\left(\mathrm{ET}_{0}\right)$ and $\mathrm{CO}_{2}$ concentration in the air, in $\mathrm{tha}^{-1}$;

Tr: Crop transpiration, in mm per time unit;

ETo: Reference evapotranspiration, in mm per time unit;

HI: Harvest index of crop j.;

$\mathrm{L}_{\mathrm{c}}$ : Labour cost, in USD wage $^{-1}$;

$\mathrm{L}_{\mathrm{jt}}$ : Amount of USD wages per growing season in one hectare, in USD ha-

$\mathrm{CI}_{\mathrm{jt}}$ : Cost of inputs (seeds, herbicide, fertilizers) in one hectare, in USD ha ${ }^{-1}$;

CR: Cost of irrigation per cubic metre, in USD m $\mathrm{m}^{-3}$;

$\mathrm{R}_{\mathrm{jt}}$ : Irrigation depth applied to the crop $\mathrm{j}$ in the growing season, in $\mathrm{mm}$.

The following constraints were used in the optimization model (Eqs. 3-7):

i. Water availability: this restriction represents the minimization of irrigation water use. The total water requirement for different crops must be less than or equal to the total water available for the local agricultural irrigation (Aw).

$$
0 \leq \sum_{t=1}^{T}\left(P P_{t}+R\right)-\left(\sum_{j=1}^{J} A_{j} \frac{T A W_{j}}{E F_{j}}\right) \leq A w
$$

where $\mathrm{PP}_{\mathrm{t}}$ is the precipitation in $\mathrm{t}, \mathrm{R}$ is irrigation. It is essential to mention that $T A W_{j}$, refers to the total available soil water after applying an initial volume of water, and $\mathrm{EF}_{\mathrm{j}}$ is the application efficiency of the irrigation system for crop $j$.

ii. Available area: the total area assigned to crops must be less than or equal to the sum of the cultivated areas in the evaluation period. The total size of the assigned land to the crops should not exceed the arable land for each simulation sub-unit, defined in 49 hectares.

$$
\sum_{j=1}^{J} A_{j} \leq A_{t}
$$

where $A_{t}$ is the land availability (in ha).

iii. Cropping area: this restriction aims to limit the assigned crops area so that it is not too small or too big and food supply can be satisfied: .

iv. Capital availability: the production cost should not exceed the total income of the spending unit in populated centres and rural areas. For each simulation sub-unit, a capital of 514.8 USD month $^{-1}$ was defined, equivalent to two updated legal monthly minimum wages (National survey of household budgets ENPH, DANE, 2017). 


$$
\begin{aligned}
& L_{c} \sum_{j=1}^{J} \sum_{t=1}^{T} A_{j} L_{j t}+\sum_{j=1}^{J} \sum_{t=1}^{T} A_{j} C I_{j t}+ \\
& +C R \sum_{j=1}^{J} \sum_{t=1}^{T} A_{j} R_{j t} \leq \sum_{t=1}^{T} \text { Income farm }_{t}
\end{aligned}
$$

v. No negativity restriction: the total area cannot be less than zero;

vi. No negativity restriction: the water requirement of the crop must be higher than zero:

$$
A w A_{j}-\sum_{j=1}^{J} A_{j} T A W_{j} \geq 0
$$

vii. Complementary considerations: To force that the water crop requirement is zero when the cropped area is also zero;

viii. Water supply: No more water than required by the crop should be applied.

$\mathrm{ET}_{\mathrm{c}}$ is the actual crop evapotranspiration

$$
T A W_{j} \leq E T C
$$

\section{Case study: Zulia River irrigation district}

The optimization model was applied to agriculture areas (45,536 hectares) of the Zulia irrigation district, located in the northeast of Colombia (latitude between $8^{\circ} 4.6^{\prime}$ and $8^{\circ} 23.0^{\prime} \mathrm{N}$ and longitude between $72^{\circ} 22.1^{\prime}$ and $72^{\circ} 35.5^{\prime} \mathrm{W}$ - Figure 2). The study area is in a warm temperate locality with a mean annual temperature that varies between $26^{\circ} \mathrm{C}$ y $28^{\circ} \mathrm{C}$, mean annual precipitations of $2487 \mathrm{~mm}$, and multiannual reference evapotranspiration of $1378.63 \mathrm{~mm}$. The altitude varies between $36 \mathrm{~m}$ and $150 \mathrm{~m}$ above sea level.

The organization of the irrigation district is dominated by small farmers, who have adopted associative integration as valid strategy for the economic development of the region and to ensure the sales of their production. Currently, 8500 hectares of surface irrigation. There is a network system for the irrigation canals composed of $410 \mathrm{~km}, 425 \mathrm{~km}$ of roadways, $32 \mathrm{~km}$ of flood control dams, and in the intake, the gravity system captures $14 \mathrm{~m}^{3} \mathrm{~s}^{-1}$, out of the $28 \mathrm{~m}^{3} \mathrm{~s}^{-1}$ that, in normal conditions, has the flow of the Zulia

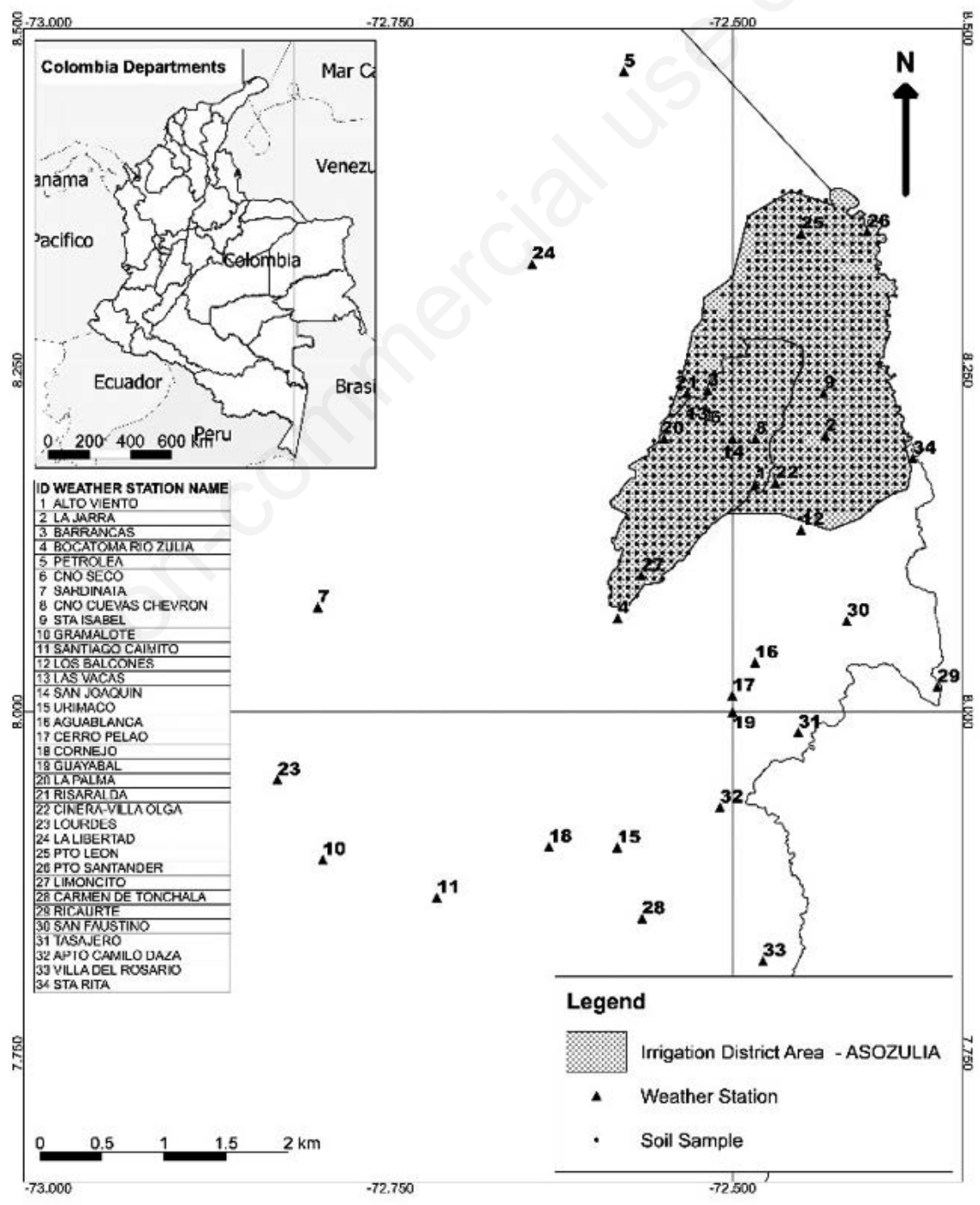

Figure 2. Study area. 
River. In the summertime, there are irrigation shifts programmed to avoid crop losses due to water deficit. In practice, the agriculture area is used for the sowing of transitory crops, mainly rice, since it allows farming families to have an income from the first harvest year.

We used AquaCrop-Os to determine crop yield (i.e., for a given crop, soil, weather, sowing date, and management). The AquaCrop-OS model was executed using the parallel run mode in MATLAB R2018b (MathWorks, 2018). This process required high computational effort, as building 97,740 scenarios (905 points or simulation sub-units for 3 reference years, 12 different sowing dates, and 3 crops) was required.

\section{Data}

\section{Meteorological data}

In this study, meteorological records were analysed for 19802010 with daily data for temperature (mean, maximum, and minimum), precipitation, and wind speed. Data were extracted from the Colombian Institute of Hydrology, Meteorology and Environmental Studies (IDEAM) database. Solar radiation information was obtained from the database AgMERRA (Ruane et al., 2015). Finally, the reference evapotranspiration in $\mathrm{mm} /$ day (ETo) was calculated using the Penman-Monteith FAO-56 method (Allen et al., 1998).

\section{Climate variability scenarios}

Based on the analysis of precipitation records for 34 meteorological stations in the study area, three scenarios of year-on-year precipitations variation were identified (Figure 3). According to the annual rainfall distribution, the climatic data were divided into wet, normal, and dry years. It was found that the precipitations frequency and intensity in 1996 was close to that of the normal year. Therefore, 1996 was selected as the average (normal) reference year. Regarding the critical years, 2010 was considered as the reference for maximum positive (excess) anomalies with $50 \%$ of excesses (wet year) and 2001 as the minimum negative (deficit) anomalies with $-42 \%$ (dry year).

\section{Soil and crop data}

Physical and hydrodynamic properties such as moisture retention curves (saturation, field capacity, permanent wilting point), bulk and real density, and the saturated hydraulic conductivity, were extracted from Agrosavia (2018). In this research, the soil samples were collected from the land surface of the irrigation district in a $0.7 \times 0.7 \mathrm{~km}^{2}$ georeferenced grid. Black dots in Figure 2 represent samples of hydrodynamic soil properties, and the triangles in the map represent the locations of the meteorological stations in the study area. Rice, corn and forage grass crops were considered for the case study. We assumed that each simulation subunits grow rice two times a year, corn three times a year. On the other hand, we assumed six different harvests per year, for forages, owing to high temperatures, sufficient solar irradiation, and available water in the study area. Yield parameters of the crops were extracted from local information and from the AquaCrop manual for the available crops. The non-conservative parameters input to the model were determined using data from local registries and, the conservative parameters were determined using data from other researchers in Colombia, who report the validations or calibrations of the crops of interest: corn and rice (Cortés-Bello et al., 2013),
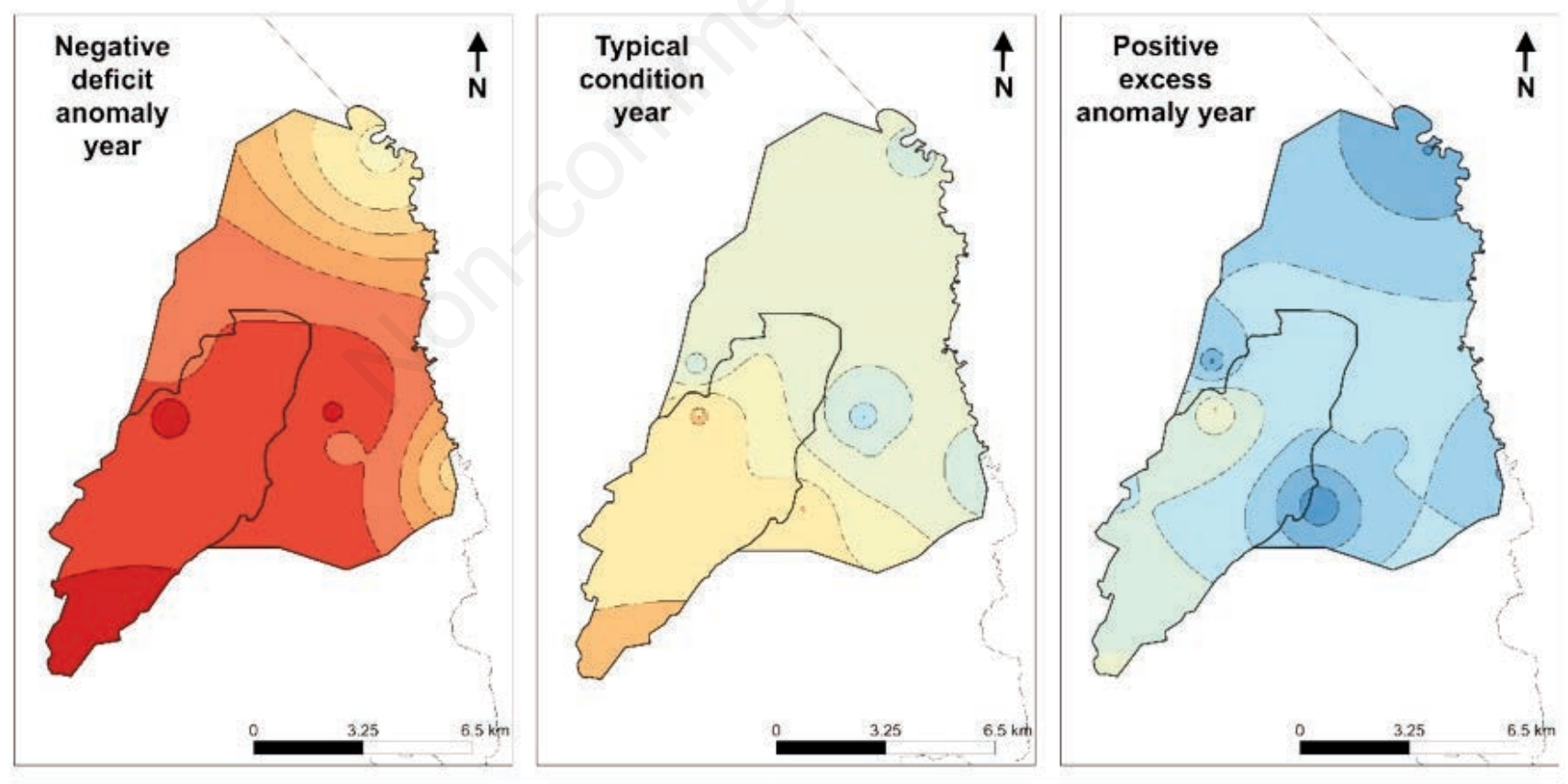

\section{Legend - Annual accumulated precipitation ( $\mathrm{mm}$ )}

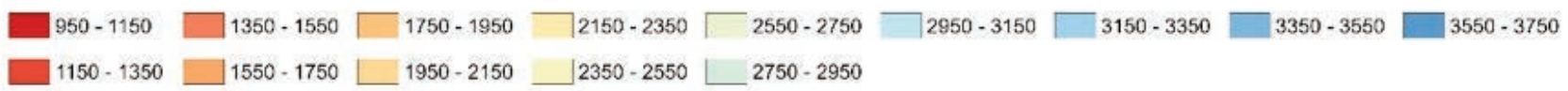

Figure 3. Spatial distribution of the annual precipitation in the study area: A) Dry year 2001; B) Normal year 1996; C) Wet year 2010. 
forages (Terán-Chaves, 2015), and calibration and validation data included in the AquaCrop reference manual carried out by different teams of researchers around the world (Foster et al., 2017). For the forage production analysis, the model was extended with additional components to simulate the beef cattle's annual yield in terms of meat production. We evaluated profitable beef production from forages in the study area. A series of assumptions were made in the present modelling exercise for Colombian native cattle Chino Santandereano (Table 1). Firstly, average dry matter intake (3.96 $\left.\mathrm{kg} \mathrm{MS} \mathrm{animal}{ }^{-1}\right)$ and average daily gain $\left(0.5 \mathrm{~kg} \mathrm{day}^{-1}\right)$. Next, we estimated efficiency at converting grazing resources into beef in $7.92 \mathrm{~kg}$ intake $\mathrm{kg}$ production ${ }^{-1}$. Finally, from estimating biomass production with the AquaCrop-OS model, we multiply the crop yield (forage) by the proxy efficiency at converting grazing resources into beef ( $\mathrm{kg}$ intake $\mathrm{kg}$ production $\left.{ }^{-1}\right)$.

The study area was divided into 905 sub-units, each of them with a $0.7 \times 0.7 \mathrm{~km}$ resolution, i.e., a $0.49 \mathrm{~km}^{2}$ grid. The crop simulation was carried out for the 12 months of each reference year. The irrigation district allocates $10000 \mathrm{~m}^{3} \mathrm{ha}^{-1}$ of water for irrigation purposes per semester. Therefore, initial soil moisture was assumed at field capacity, and we used net irrigation calculation.

\section{Economic data}

The production costs were obtained from The Colombian Agricultural Research Corporation databases, the sales price from the database Price and supply information system of the agricultural and livestock sector-food supply component of The National Administrative Department of Statistics. Table 2 shows the reference data of the selected crops, costs, and prices. The exact value daily wage for agricultural labour, 8.57 USD day $^{-1}$ ( 8 hours of work), was considered for the three crops and water purchase price of $0.01 \mathrm{USD} \mathrm{m}^{-3}$. The prices were adjusted to October 2020 using the Consumer Index Prices (IPC) calculator. For this study, a value of 3500 Colombian pesos (COP) was considered per US dollar (USD). All the agriculture parameters, including prices, remained constant throughout the simulation. Therefore, the only source of variation between different study years is the effect of climate.

\section{Results and discussion}

The appropriate cropping pattern according to the available resources, the economic profitability, and the optimal irrigation depths are presented in this section. The model assumes each month's first day as the start of the sowing. We used a K-means spatial clustering algorithm based on the net profitability. The statistical spatial clustering identified 4 different groups (Figure 4). The spatial clustering results indicated that the dry year led to

Table 1. Parameter and assumptions for the production animal.

\begin{tabular}{lc} 
Parameter & Value \\
Heads per hectare & 10 \\
Body weight of the animal $(\mathrm{kg})$ & 180 \\
\hline Average dry matter intake $\left[\mathrm{kg} \mathrm{MS} \mathrm{animal}^{-1}\right]$ & 3.96 \\
Average daily gain $\left[\mathrm{kg} \mathrm{day}^{-1}\right]$ & 0.5 \\
\hline Efficiency at converting grazing resources into beef & 7.92 \\
\hline $\mathrm{kg}^{-1}$ intake kg production & \\
\hline
\end{tabular}

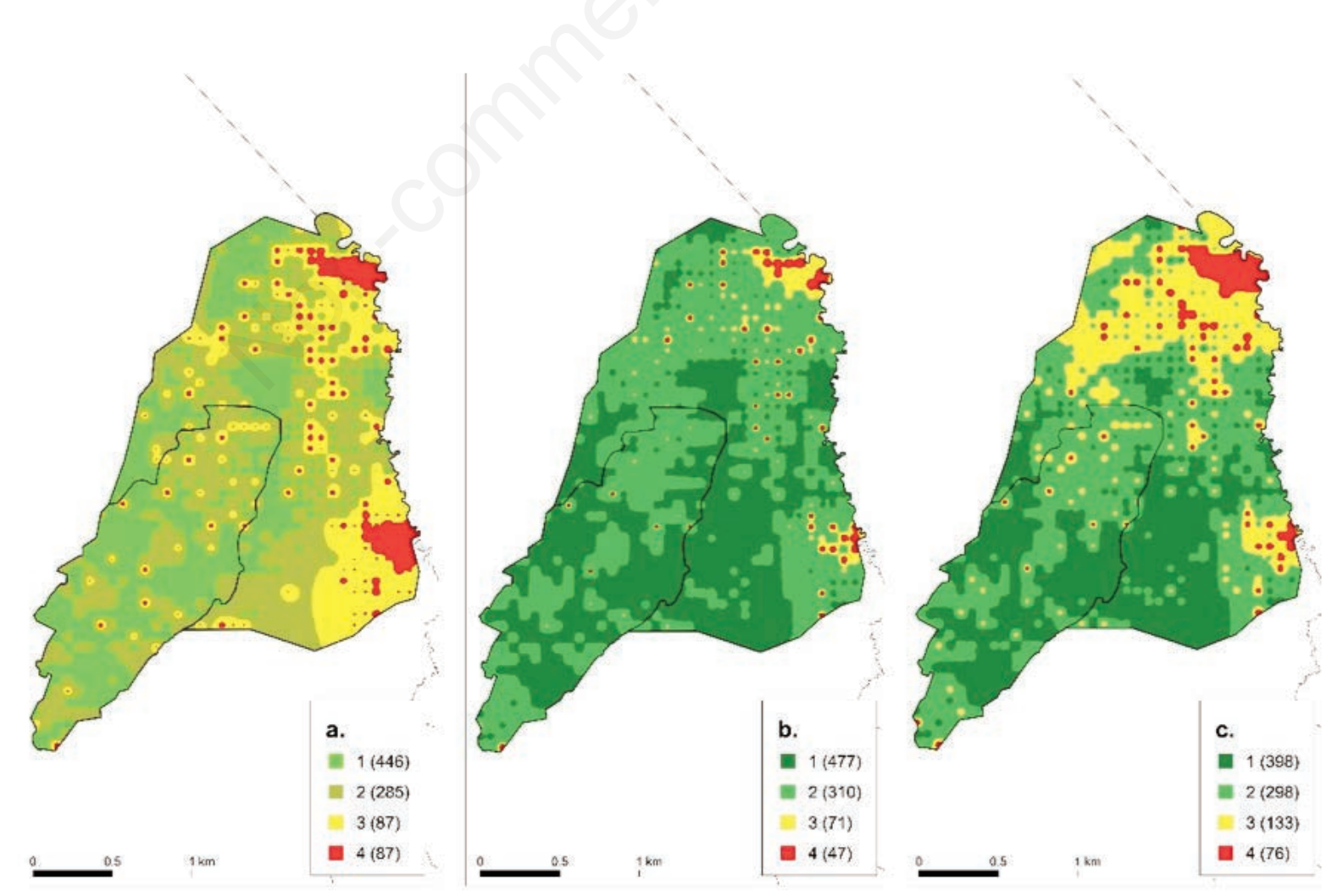

Figure 4. Cluster Net profitability: A) Dry year 2001; B) Normal year 1996; C) Wet year 2010. 
lower profitability. In contrast, the normal and wet years showed higher returns. Moreover, for each group, the spatial-temporal heterogeneity of net profitability is shown in Table 3 .

In a dry year, the total study area covered by cluster 1 , followed by cluster 2 , cluster 3 , and cluster 4 was approximately $49.28 \%, 31.49 \%, 9.61 \%$, and $9.61 \%$, respectively. On average, because of the optimization process for a 49 hectares surface, the net profitability was 43,700 USD per year in cluster 1 . For cluster 2 a net profitability of 37,200 USD per year was obtained. For cluster 3 an average net profitability of 24,000 USD per year was obtained, and for cluster 4 an average net profitability of 2,900 USD per year was obtained. Thus, the model shows areas unsuitable for agriculture production. In these cases, water resources management could be a good option to increase the profit levels.

In the normal year and once the production resources were optimized, the total area covered by cluster 1 was 23,997 hectares, equivalent to $52.7 \%$ of the total study area. The average net profitability of cluster 1 for a 49 hectares surface (simulation sub-unit) was 51,100 USD per year, and 44,200, 30,300, and 5620 USD for clusters 2, 3, and 4, respectively. For the wet year scenario, the profitability levels resulted similar compared to the normal year optimization results.

Figure 5 shows for each agroclimatic scenario the optimal cropping patterns for the study area and the net profitability for each month sowing (period), which can vary between 0 and 50 thousand USD. According to the water deficit conditions results, rice and corn crops represent the optimal combination for $83.7 \%$ of the Zulia irrigation district area, with profitability levels that vary
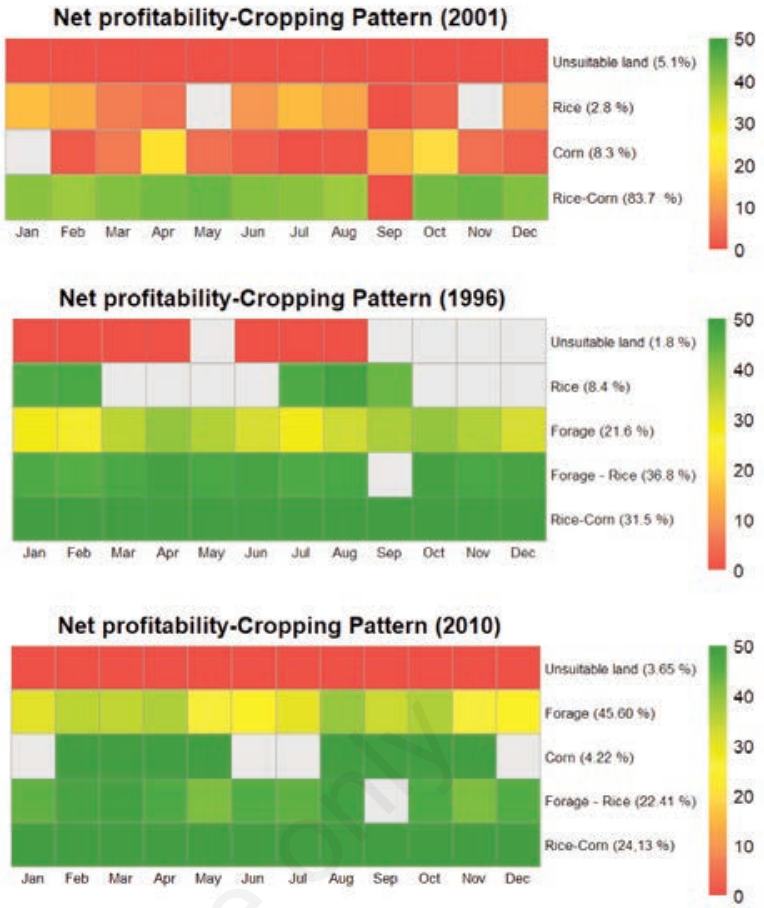

Figure 5. Net profitability-cropping pattern (in thousands of USD) for reference years: A) Dry year 2001; B) Normal year 1996; C) Wet year 2010.

Table 2. Parameters and input data for each crop.

\begin{tabular}{|c|c|c|c|}
\hline Input & Rice & Corn & Forage \\
\hline Historical average crop yields $\left[\mathrm{kg} \mathrm{ha}^{-1}\right]$ & 5000 & 3000 & $1869 *$ \\
\hline Price [USD kg-1] & 0.29 & 0.21 & 1.24 \\
\hline Gross value of production [USD ha-1] & 1442.86 & 617.14 & 2313.97 \\
\hline Hired labour-days (person days per hectare) & 9.00 & 11.00 & 20.00 \\
\hline Operating costs: seed, fertilizer, chemicals [USD ha-1] & 815.94 & 339.71 & 1118.30 \\
\hline Machinery rental rate (average rate for agricultural operations) [USD ha-1] & 496.79 & 148.57 & 27.14 \\
\hline
\end{tabular}

*Kilograms beef live-weight per hectare.

Table 3. Clustering k-means net profitability (in thousands USD).

\begin{tabular}{|c|c|c|c|c|c|c|c|c|c|c|c|c|}
\hline \multirow{2}{*}{$\begin{array}{l}\text { Sow. } \\
\text { date }\end{array}$} & \multicolumn{4}{|c|}{ Dry year (2001) } & \multicolumn{4}{|c|}{ Normal year (1996) } & \multicolumn{4}{|c|}{ Wet year $(2010)$} \\
\hline & C1 & $\mathrm{C} 2$ & C3 & C4 & C1 & $\mathrm{C} 2$ & C3 & $\mathrm{C} 4$ & C1 & $\mathrm{C} 2$ & C3 & $\mathrm{C} 4$ \\
\hline Jan & 44.1 & 38.7 & 24.6 & 2.8 & 51.6 & 45.8 & 30.5 & 5.9 & 49.1 & 39.2 & 24.8 & 4.1 \\
\hline Feb & 43.6 & 36.7 & 21.7 & 1.7 & 52.3 & 43.2 & 26.3 & 3.6 & 48.7 & 39.5 & 23.6 & 2.2 \\
\hline Mar & 46.4 & 38.6 & 23.2 & 2.1 & 51.9 & 42.9 & 30.4 & 5.9 & 49.7 & 38.6 & 24.7 & 4.1 \\
\hline Apr & 47.7 & 40.2 & 25.5 & 3.1 & 50.4 & 44.1 & 31.7 & 6.0 & 54.7 & 42.8 & 29.8 & 5.6 \\
\hline May & 48.9 & 43.4 & 31.1 & 4.3 & 50.1 & 42.9 & 30.4 & 5.9 & 53.9 & 40.8 & 24.7 & 4.1 \\
\hline Jun & 45.7 & 41.0 & 29.3 & 4.3 & 51.3 & 46.4 & 31.8 & 6.0 & 52.4 & 47.0 & 30.8 & 5.6 \\
\hline Jul & 44.1 & 38.7 & 24.6 & 2.8 & 51.6 & 45.8 & 30.5 & 5.9 & 49.1 & 39.2 & 24.8 & 4.1 \\
\hline Aug & 43.6 & 36.7 & 21.7 & 1.7 & 52.4 & 45.4 & 31.7 & 6.0 & 49.3 & 42.7 & 29.8 & 5.6 \\
\hline Sep & 18.4 & 7.8 & 0.3 & 0.0 & 50.1 & 40.1 & 26.8 & 3.7 & 48.4 & 36.4 & 22.2 & 2.8 \\
\hline Oct & 47.7 & 40.2 & 25.5 & 3.1 & 50.4 & 44.1 & 31.7 & 6.0 & 54.7 & 42.8 & 29.8 & 5.6 \\
\hline Nov & 48.9 & 43.4 & 31.1 & 4.3 & 50.1 & 42.9 & 30.4 & 5.9 & 53.9 & 40.8 & 24.7 & 4.1 \\
\hline Dec & 45.7 & 41.0 & 29.3 & 4.3 & 51.3 & 46.4 & 31.8 & 6.0 & 52.4 & 47.0 & 30.8 & 5.6 \\
\hline Mean & 43.7 & 37.2 & 24.0 & 2.9 & 51.1 & 44.2 & 30.3 & 5.6 & 51.4 & 41.4 & 26.7 & 4.4 \\
\hline Min & 18.4 & 7.8 & 0.3 & 0.0 & 50.1 & 40.1 & 26.3 & 3.6 & 48.4 & 36.4 & 22.2 & 2.2 \\
\hline Max & 48.9 & 43.4 & 31.1 & 4.3 & 52.4 & 46.4 & 31.8 & 6.0 & 54.7 & 47.0 & 30.8 & 5.6 \\
\hline $\bar{A}$ & \multicolumn{4}{|c|}{977} & \multicolumn{4}{|c|}{1010} & \multicolumn{4}{|c|}{895} \\
\hline B & \multicolumn{4}{|c|}{9871} & \multicolumn{4}{|c|}{9838} & \multicolumn{4}{|c|}{9953} \\
\hline $\mathrm{C}$ & \multicolumn{4}{|c|}{0.91} & \multicolumn{4}{|c|}{0.91} & \multicolumn{4}{|c|}{0.92} \\
\hline
\end{tabular}

A, the total within-cluster sum of squares; B, the between-cluster sum of squares; $C$, the ratio of between to total sum of squares. 
between 45 and 50 thousand USD throughout 11 periods. The month of September is considered unsuitable for crop planting because a negative net benefit per hectare was obtained in this period. In the normal year, the combination of rice and corn resulted optimal for $31.5 \%$ of the district area for the 12 months of crop planting evaluated, with profitability levels that vary between 45 and 50 thousand USD. The combination forage-rice resulted optimal for the $36.8 \%$ of the productive area of the irrigation district with profitability levels that vary between 40 and 45 thousand USD. The forage system evaluated in terms of meat production resulted optimal in $21.6 \%$ of the productive area, with profitability levels that vary between 35 and 45 thousand USD. The periods that showed the lowest profit were January, February, and July.

In the water excess scenario (wet year), the forage crop proved to be the best option at a regional level, with net profitability that varied from 25 and 35 thousand USD. The cropping pattern ricecorn resulted optimal for the $24.1 \%$ of the agriculture area with profit levels from 40 and 50 thousand USD. The cropping pattern forage-rice resulted optimal in $22.4 \%$ of the irrigation district area. In this scenario, the unsuitable area for agriculture production was $3.65 \%$. The difference in the spatial distribution of crops was affected by the adaptability of the units' simulation to climate variability conditions.

The results obtained for the rice and forage crops distribution are very similar to the current situation. According to the optimization data, the forage area resulted big, while the corn area resulted small. Therefore, combined cropping rice with forage grasses is a potential strategy for enhancing the sustainability of agriculture in the tropical region by increasing food production, land use per unit area, nitrogen (N) cycling, and profitability (Crusciol et al., 2021). Furthermore, the optimization model proposed in this paper improves the irrigation water productivity and crop yields and provides a methodological basis for the sustainable use of local water resources and sustainable agricultural development.

Compared with the income of an average farmer in the zone, the crop net benefits of the optimized scenarios have increased. In other words, the benefits and efficiency of agricultural water use have been improved, which will positively impact future agricultural irrigation in the study area. Furthermore, the study area could obtain high economic benefits if rice intercrop with forage grasses in an integrated crop-livestock system.

When there is not a viable solution for the model, the algorithm considers the area as unsuitable lands. This happens when, given the biophysical or economic conditions, it is not feasible to define a cropping pattern in the supervised area.

In the Zulia irrigation district, the water concession per hectare is $10,000 \mathrm{~m}^{3}$ per semester, equivalent to a water volume of 1000 $\mathrm{mm}$ depth. Figure 6 shows the optimal distribution of the irrigation depth that maximizes the crops' economic benefit and minimizes both operating costs and the water deficit of crops. The results show that temporal variability of the irrigation depth reached its highest value in the dry year, with a range between $800 \mathrm{~mm}$ to $1200 \mathrm{~mm}$. Next was the normal year, with a range between 185 $\mathrm{mm}$ to $610 \mathrm{~mm}$, and the lowest value was obtained for the wet year with a range from $109 \mathrm{~mm}$ to $318 \mathrm{~mm}$. Therefore, according to $\mathrm{Li}$ et al. (2020), a simulation-optimization model can provide a technical method for developing irrigation programs. This would ensure crops profitability and irrigation water savings for multiple scenarios, particularly in water deficit periods.

In the dry year, it is noted that the water requirement was the highest $(>=1200 \mathrm{~mm}$ ) in September. Therefore, this period resulted unsuitable for cropping. The rice-corn cropping pattern shows the optimal water requirement for $83.1 \%$ of the evaluated area with an average water demand of $700 \mathrm{~mm}$.

In the normal year scenario, the combinations forage-rice and rice-corn maximize the profits in most areas. If the crops' water demand is optimized for each simulated period $(500 \mathrm{~mm})$, up to $50 \%$ of water could be saved. Wet year conditions, the cropping patterns are profitable with $300 \mathrm{~mm}$ to $400 \mathrm{~mm}$ irrigation depths during most of the simulated crop periods, and predominated patterns were forages.

It is worth noting that the $\mathrm{C} 4$ species such as forage grasses are more efficient in converting energy intercepted by the canopy into biomass production (Zhou et al., 2015), in scenarios low doses of radiation on the crop, resulting in faster growth compared with $\mathrm{C} 3$ species such as rice (Karki et al., 2013). In general, high forage yield could be associated with higher projected higher meat. These parameters are relevant for farmers who need to provide food to livestock through mechanical harvest or grazing (Pariz et al., 2017) can also improve crop systems sustainability in tropical regions (Crusciol et al., 2021).

The profit and irrigation depth combined model presents great advantages to achieve resources optimization and maximize returns. For instance, in the rice-corn production system of the dry year scenario, the irrigation depth is optimized, as Figure 6 shows, since the water requirement level is the lowest compared to the other production systems. This is similar for the forage-rice production system in the average scenario and the rice-corn in the water excess scenario.

Similar to the findings of Moraes et al. (2019), our results support a combination of crops as a feasible option for increasing sustainability in tropical areas by creating opportunities for farmers to seek greater revenue, furthermore, as these systems can increase global food production without increasing the area of cultivation, under different climate change scenarios. Our data indicate that
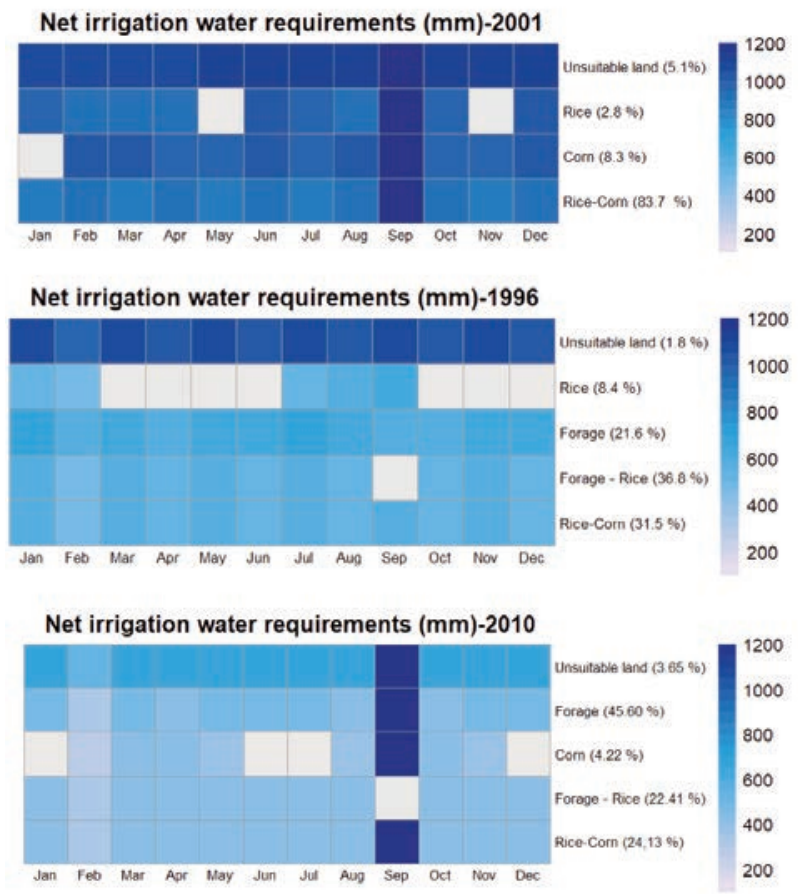

Figure 6. Net irrigation water requirements (NIWR) in $\mathrm{mm:} \mathrm{A}$ ) Dry year 2001; B) Normal year 1996; C) Wet year 2010. 
rice combined with forage grasses will be a promising approach for farmers, above all in these tropical regions in condition wet year. This result is consistent with findings from Crusciol et al. (2021).

In general, improving the utilization rate of water can save irrigation water without reducing crop yield, which has vital meaning for food security, health, livelihoods for poor people, and sustainable development of arid and semi-arid regions (Mohammadzadeh et al., 2020). Moreover, related studies have proved that these optimization measures have great potential in developing agricultural water-saving (Tan and Zheng, 2019; Fan et al., 2021).

This study illustrated the importance of the cropping pattern simulation-optimization model for water use efficiency and economic return optimization; even though rice yield may be lower, the farmer can generate additional income due to meat production and improved land use.

\section{Conclusions}

The model can achieve a cropping pattern and optimal water volume based on space grids and different crop growth periods. The objective function included a water productivity model (AquaCrop-OS) adjusted to the spatio-temporal patchiness of soil and rainfall. In the study case applied to the Zulia irrigation district, different optimization schemes were obtained for the normal year (1996), the wet year (2010), and the dry year (2001).

The main advantage of considering a multiple period model is that it is the best option to deal with climate variability and analyse its effect on the productive system's yield and economic profitability according to the water regime scenario and the sowing dates.

The rice-corn combination has the best net profitability for all climate scenarios. For this reason, a more diverse planting structure should be encouraged to replace rice monocropping with a rice-corn dual crop for responding to variations in the precipitation regime. Although of lower net profitability, the cropping pattern of the highest coverage was obtained in the normal year for the forage-rice combination in $36.8 \%$ of the area, and in the wet year for the forage with a coverage of the $45.6 \%$ of the area.

The simulation-optimization framework developed allowed us to estimate the effect of climate variability on a cropping pattern's yield developed for the study area. On average, in a dry year, the net profitability can decrease up to $14.5 \%$ compared to a normal year in half of the area. This could result in a profits reduction of up to $53 \%$. In the wet year, profitability remains at the same level in $43.8 \%$ of the area compared to the normal year. However, in $23.1 \%$ of the district, there were considerable reductions in profits.

The optimal irrigation demand varied significantly among the different meteorological years established in this study. In the dry year, the cropping pattern rice-corn generates the optimal water requirement for $83.1 \%$ of the evaluated area with an average water demand of $700 \mathrm{~mm}$. In the normal year, the water demand of the crops for each simulated period was on average $500 \mathrm{~mm}$, which could allow to save up to $50 \%$ of water compared to the current concession, which is $1000 \mathrm{~mm}$. In wet year conditions, the crop patterns resulted profitable with $300 \mathrm{~mm}$ to $400 \mathrm{~mm}$ irrigation depths during most crop simulated periods.

These results could be useful for the formulation of a regulatory and operational framework in the study area to ensure crop yields and save irrigation water consumption. This type of analysis can be used to adapt prevention and mitigation strategies to temporal and spatial-specific agroclimatic conditions. However, management decisions to that profit-maximization are conducted at differ- ent spatial levels from the field (farm or irrigation district) to territorial entities. Our study provides an example of how to plan future management at different scales and how resource allocation should be evaluated as spatio-temporal patterns of the crop that do not naturally follow administrative spatial units (e.g., municipalities or departments).

The difference between the current crops' patterns situation of the optimized area and the ones obtained in the optimization model shows the importance of combination biophysical and economic models to determine resource optimization in variability and climate change scenarios. Furthermore, this model can be applied to other arid and semi-arid regions to help solve the problem of unreasonable use of irrigation water resources and thus comprehensively enhance the agricultural economy and environment of these areas.

In the future, the combination of crop models and economic optimization models will be considered to optimize the yield crop and crop water consumption on a monthly or daily scale, for instance, AquaCrop-OS with information times series prices and costs regionals. In addition, to prevent an intensive increase in cultivation area for some crops, the model can be designed to adapt water prices dynamically in different zones for each crop. Therefore, we suggest considering any water price function for the users and crops

Furthermore, an agent-based model could be developed to account for the role of interactions among agents in determining crop patterns and area allocation. We also recommended including the participatory approach with the mathematical optimization to derive acceptable solutions in land use allocation.

\section{References}

Allen R., Pereira L., Raes D., Smith M. 1998. Crop evapotranspiration: guidelines for computing crop water requirements. FAO 56 - Food and Agriculture Organization of the United Nations, Roma, Italy.

Anselin L., Syabri I., Kho Y. 2006. GeoDa: an introduction to spatial data analysis. Geogr. Anal. 38:5-22.

Arthur D., Vassilvitskii S. 2007. k-means++: The advantages of careful seeding. pp 1027-35 in SODA 07, Proceedings of the Eighteenth Annual Acm-Siam Symposium on Discrete Algorithms, edited by Harold Gabow, Society for Industrial and Applied Mathematics, Philadelphia, PA, USA.

Bello Z.A., Walker S. 2016. Calibration and validation of AquaCrop for pearl millet (Pennisetum glaucum). Crop Pasture Sci. 67:948.

Cortés-Bello C.A., Bernal-Patiño J.G., Díaz-Almanza E.D., Méndez-Monroy J.F. 2013. Uso del modelo AquaCrop para estimar rendimientos para el cultivo de maíz en los departamentos de Córdoba, Meta, Tolima y Valle del Cauca. FAO, Bogotá, DC, Colombia.

Crusciol C.A., Momesso L., Portugal J.R., Costa C.H., Bossolani J.W., Costa N.R., Pariz C.M., Castilhos A.M., Rodrigues V.A., Costa C., Franzluebbers A.J., Cantarella H. 2021. Upland rice intercropped with forage grasses in an integrated crop-livestock system: Optimizing nitrogen management and food production. Field Crops Res. 261:108008.

Daghighi A., Nahvi A., Kim U. 2017. Optimal cultivation pattern to increase revenue and reduce water use: application of linear programming to arjan plain in fars province. Agriculture. 7:73.

DANE. National Administrative Department of Statistics of Colombia. 2017. National survey of household budgets - 


\section{ENPH.}

Doorenbos J., Kassam A. 1979. Yield response to water. Food and Agriculture Organization, Rome, Italy.

Fan Y., He L., Kang S., Wang S., Fang Y. 2021. A novel approach to dynamically optimize the spatio-temporal distribution of crop water consumption. J. Clean. Prod. 310:127439.

Foster T., Brozović N., Butler A.P., Neale C.M.U., Raes D., Steduto P., Fereres E., Hsiao T.C. 2017. AquaCrop-OS: an open-source version of FAO's crop water productivity model. Agric. Water Manag. 181:18-22.

Hadebe S.T., Modi A.T., Mabhaudhi T. 2017. Calibration and testing of AquaCrop for selected sorghum genotypes. Water SA. 43:209.

Hart W.E., Laird C.D., Watson J., Woodruff D.L., Hackebeil G.A., Nicholson B.L., Siirola J.D. 2017. Pyomo - Optimization modeling in Python. 2nd rev. ed. Springer International Publishing, Boston, MA, USA.

He L., Bao J., Daccache A., Wang S., Guo P. 2020. Optimize the spatial distribution of crop water consumption based on a cellular automata model: a case study of the middle Heihe River basin, China. Sci. Total Environ. 720:137569.

Hoon M.D., Imoto S., Miyano S. 2017. The C clustering library. The University of Tokyo, Institute of Medical Science, Human Genome Center, Tokyo, Japan.

IDEAM. Instituto de Hidrología, Meteorología y Estudios Ambientales. 2018. Estudio nacional del agua. Bogotá, DC, Colombia.

Karki S., Rizal G., Quick W.P. 2013. Improvement of photosynthesis in rice (Oryza sativa L.) by inserting the $\mathrm{C} 4$ pathway. Rice $6: 1$.

Kuschel-Otárola M., Rivera D., Holzapfel E., Palma C., GodoyFaúndez A. 2018. Multiperiod optimisation of irrigated crops under different conditions of water availability. Water 10:1434.

Lorite I.J., García-Vila M., Santos C., Ruiz-Ramos M., Fereres E. 2013. AquaData and AquaGIS: two computer utilities for temporal and spatial simulations of water-limited yield with AquaCrop. Comput. Electron. Agric. 96:227-37.

Li J., Jiao X., Jiang H., Song J., Chen L. 2020. Optimization of Irrigation Scheduling for Maize in an Arid Oasis Based on Simulation-Optimization Model. Agron.10: 935.

Liu X., Guo P., Li F., Zheng W. 2019. Optimization of planning structure in irrigated district considering water footprint under uncertainty. J. Clean. Prod. 210:1270-80.

Mardani M., Ziaei S., Nikouei A. 2019. Optimal cropping pattern modifications with the aim of environmental-economic decision making under uncertainty. IJAMAD 8:365-75.

MathWorks. 2018. Parallel computing toolbox: user's guide; technical report. The MathWorks, Inc.: Natick, MA, USA.

Mohammadzadeh A., Vafabakhsh J., Mahdavi Damghani A., Deihimfard R. 2020. Optimal land allocation to crop production in different decision priorities and water availability scenarios: East Azerbaijan province of Iran. Arch. Agron. Soil Sci. $1-18$.

Moraes A., Alexandre C., Crusciol C., Lang C., Pariz C., Deiss L., Sulc R., De Faccio Carvalho P. 2019. Integrated crop-livestock systems as a solution facing the destruction of pampa and cerrado biomes in South America by intensive monoculture systems. Academic Press, New York, NY, USA.
Ouyang Z., Zheng H., Xiao Y., Polasky S., Liu J., Xu W., Wang Q., Zhang L., Xiao Y., Rao E., Jiang L., Lu F., Wang X., Yang G., Gong S., Wu B., Zeng Y., Yang W., Daily G.C. 2016. Improvements in ecosystem services from investments in natural capital. Sci. 352:1455-9.

Pahmeyer C., Kuhn T., Britz W. 2021. 'Fruchtfolge': A crop rotation decision support system for optimizing cropping choices with big data and spatially explicit modeling. Comput. Electron. Agric.181:105948.

Pariz C.M., Costa C., Crusciol C.A., Castilhos A.M., Meirelles P.R., Roça R.O., Pinheiro R.S., Kuwahara F.A., Martello J.M., Cavasano F.A., Yasuoka J.I., Sarto J.R., Melo V.F., Franzluebbers A.J. 2017. Lamb production responses to grass grazing in a companion crop system with corn silage and oversowing of yellow oat in a tropical region. Agric. Syst. 151:111.

Pei W., Guo X., Ren Y., Liu H. 2021. Study on the optimization of staple crops spatial distribution in China under the influence of natural disasters. J. Clean. Prod. 278:123548.

Rădulescu C.Ț.Z., Rădulescu M. 2012. A decision support tool based on a portfolio selection model for crop planning under risk. Stud. Inform. Control. 21:377-82.

Raes D., Steduto P., Hsiao T. C., Fereres E. 2009. AquaCrop-The FAO crop model to simulate yield response to water: II. Main algorithms and software description. Agron. J. 101:438-47.

Ruane A.C., Goldberg R., Chryssanthacopoulos J. 2015. Climate forcing datasets for agricultural modeling: Merged products for gap-filling and historical climate series estimation. Agric. Forest Meteorol. 200:233-48.

Steduto P., Hsiao T.C., Raes D., Fereres E. 2009. AquaCrop-The FAO crop model to simulate yield response to water: I. Concepts and underlying principles. Agron. J. 101:426-37.

Sylvester J., Valencia J., Verchot L.V., Chirinda N., Romero Sanchez M.A., Quintero M., Castro-Nunez A. 2020. A rapid approach for informing the prioritization of degraded agricultural lands for ecological recovery: A case study for Colombia. J. Nat. Conserv. 58:125921.

Tan M., Zheng L. 2019. Increase in economic efficiency of water use caused by crop structure adjustment in arid areas. J. Environ. Manage. 230:386-91.

Terán-Chaves C.A. 2015. Determinación de la huella hídrica y modelación de la producción de biomasa de cultivos forrajeros a partir del agua en la Sabana de Bogotá (Colombia). Degree Diss. Universitat Politècnica de València, España.

World Bank. 2020. Agriculture, forestry, and fishing, value added (constant 2010 US\$) - Colombia https://data.worldbank. org/indicator/NV.AGR.TOTL.ZS

Yeşilköy S., Şaylan L. 2020. Assessment and modelling of crop yield and water footprint of winter wheat by AquaCropItal. J. Agrometeorol. 1:3-14.

Zeleke K.T. 2019. AquaCrop calibration and validation for Faba Bean (Vicia faba L.) under different agronomic managements. Agron. 9:320.

Zhou L., Liang S., Ponce K., Marundon S., Ye G., Zhao X. 2015. Factors affecting head rice yield and chalkiness in indica rice. Field Crops Res. 172:1-10. 